\title{
COLLABORATIVE AND PARTICIPATORY DESIGN: ASSIGNMENT OF TEAM MEMBERS TO ENGINEERING PROJECTS WITH THE CONSIDERATION OF DESIGNER'S EXPECTATIONS
}

\author{
JIN, Guangying; Sperandio, Séverine; Girard, Philippe \\ IMS, UMR 5218 University of Bordeaux, 351 Cours de la libération, 33405 Talence cedex, France
}

\begin{abstract}
With the trend of global collaboration and development of Internet of Things in industry 4.0, the collaboration relationships between designers is getting more close and important than before. Therefore, when project manager assign designers to design projects, it is very important for them to select design projects with the consider about the expectations of the designers regarding the different projects and collaboration ability for the designers in the projects while it is very important to identify the projects with the consideration of skills, experiences, availabilities and so on. Even though, there are various methods for selecting projects, most of these methods not consider about the expectations of designer and the collaboration ability. Therefore, in this paper, we propose a project selection methodology, which consider about the designers' expectations to the candidate multi-project and collaboration ability in the candidate multi-project. The main objective of our research is to help project manager to find an adaptable and comfortable multi- project to the designer
\end{abstract}

Keywords: Collaborative design, Project management, Teamwork, Project selection, Designer expectations

Contact:

JIN, Guangying

Université de Bordeaux

IMS, UMR5218

France

guangying.jin@u-bordeaux.fr

Cite this article: JIN, G., Sperandio, S., Girard, P. (2019) 'Collaborative and Participatory Design: Assignment of Team Members to Engineering Projects with the Consideration of Designer's Expectations', in Proceedings of the 22nd International Conference on Engineering Design (ICED19), Delft, The Netherlands, 5-8 August 2019. DOI:10.1017/ dsi.2019.9 


\section{INTRODUCTION}

In collaborative and participatory design, it is important to select satisfactory design projects for the designers. Available project alternatives usually far exceed the number of projects, and choosing the right projects in a particular context is seldom easy (Engwall and Jerbrant, 2003). Therefore, academics and practitioners alike have sought to develop methods to address the project selection problem (Kaiser et al., 2015).

For the Project Management Triangle (Thorne, 2016), in which is explained that quality of work is constrained by the project's budget, deadlines and scope, is a model of the constraints of project management.

Studying 7,939 business units, Gallup researchers found significant connections between employee expectation and the business unit outcomes of customer expectation, productivity, profit, employee turnover and accidents (Stringer, 2013). Therefore, it is better for the project manager to position designers in projects (multi-project), according their skills, knowledge and expectation. In here, the expectation is related to the personal responsibilities, workload, work environment, salary and so on. Apart from that, depending on the rapid development of global internet of things (IoT) (Gubbi et al., 2013) in Industry 4.0, the product design members can collaborate more frequent and closer than before. Therefore, the success of project does not depend only on the expertise of the people, but also quite importantly on how effectively they collaborate (Karageorgos, 2015). The collaboration relationship in the design project team becomes more important for future design project selection. Apart from that, it is difficult for the project manager to grasp and manage the expectation of designer and collaboration ability when the project manager assigns select candidate projects to the designers.

Therefore, In order to maximize the interests and support project manager, it is very urgent for the company to have another automatic resource assignment tool (project selection tool) which considers about expectation and collaboration effectiveness of employees (resource) from available projects.

Hence, according to the problems we have discussed above, the main objective of this research is to help project manager to approach the design project selection problem with the consideration of the designer expectation and collaboration ability.

The remainder of this paper is organized as follows. Section "Literature Review" recalls the importance of expectation of designer and collaboration ability. In Section "Design Project Selection Methodology", we introduce the whole process of design project selection methodology. Section "Analysis of an example" describes a scenario to depict experimental details and simulation results. Finally, a simple conclusion will be illustrated in Section "Conclusion".

\section{LITERATURE REVIEW}

The success of project selection ensures the completion of project in time, within budget, and to the project specifications (insuring the quality) (Babu and Suresh, 1996). Meanwhile, the trade-off problem among delay, cost and quality is very difficult task and important problem for the project management (Tavana et al., 2014). Apart from that, the behaviors, attitudes, organizations and collaboration relationships for designers will affect the criteria of cost, delay, quality of design project (Figure 1).

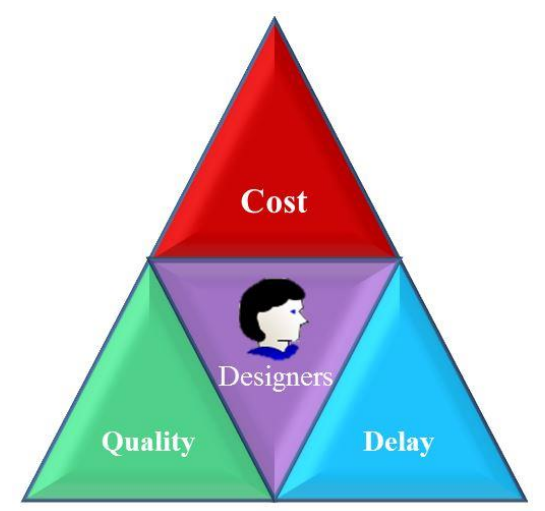

Figure 1. Relationship between designers and quality, delay and cost of project 
In the Figure 1, we can find that the designer can influence the quality, delay and cost of the project. In here, one of the reasons for the influence is designer's expectation with various factors (personal responsibility, work environment, salary and so on) of the positioned projects. Another reason is the designer's collaboration ability with other collaborated designers in the positioned projects.

The expectation of employees with their jobs and leaders has been extensively studied in the business and organizational communication fields (Men, 2014). Low employee expectation has been recognized by scholars as a negative consequence of bad human resource allocation processes (Loredo and Picos, 2014). The expectation of the employee is related to the different kinds and levels of the needs for the employee. Maslow (1943) stated that people are motivated to achieve certain needs, and when one need is fulfilled a person seeks to fulfill the next one (McLeod, 2007). The project manager decides on an appropriate organisation, called the design environment, to encourage collaboration among designers. (Girard and Robin, 2006).

Because of the reason that the IoT (Internet of Things) (Lee et al., 2015) supports project managers to find the adaptable design projects very easily from all over the world, to consider about expectation of the designer to the positioned design project will be more respected. Meanwhile, the collaboration relationships between designers are getting more close than before. Therefore, in the factory of the future, the analysis of collaboration ability in the design project will be more important.

When project managers want to select design projects, it is very important for them to consider about the expectation for the designer to the selected projects and collaboration ability among designers in the selected projects. Although numerous project selection methodologies have been proposed to treat project selection problem, there is no method that takes into account designer's expectation to design project and collaboration ability between designers in design project.

Hence, our main objective is to propose a project selection methodology with the consideration of expectation influence factors for the designer and collaboration ability, and the methodology can help project manager to select most comfortable multi-project to designer.

\section{DESIGN PROJECT SELECTION METHODOLOGY}

Our starting hypothesis is this: we have a team of designers to assign to engineering projects. The objective is therefore to identify which projects could correspond to the skills, experiences, availabilities, and so on of our designers. The originality of the methodology is that it takes into account, in addition to the classic criteria of assignment, the expectations of the designers regarding the different projects. The whole process of design project selection in this paper can be seen in the Figure 2.

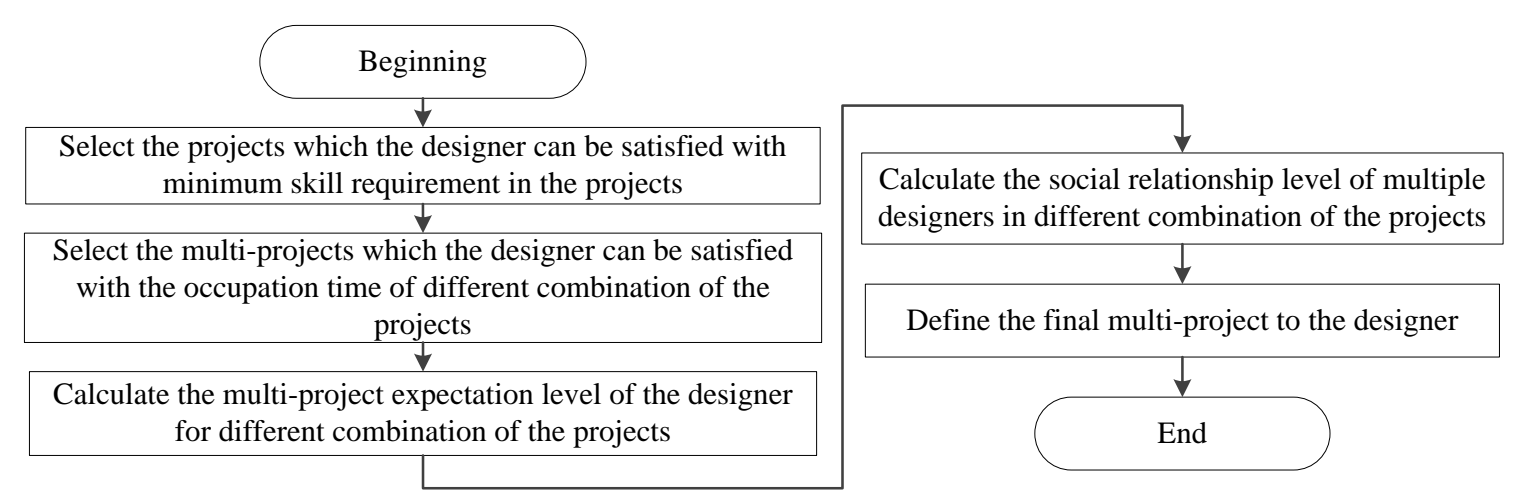

Figure 2. Process diagram for design project selection methodology

First of all, we should select the projects which the designer can be satisfied with the minimum skill requirement in the project. In here, the skill requirement for design project can be UI (user interface) design, graphic design basics, design software, and etc. After that we will make further selection of multi-projects which the designer can be satisfied with the occupation time of different combination of the projects. Afterwards, we have to calculate the multi-projects expectation level of the designer and collaboration level of multiple designers for different combination of the projects. At the final, we will define the final multi-project to the designer, and the process will be finished. 


\subsection{Select the projects with the constraints of minimum skill requirement and occupation time in candidate projects}

For every design project, there will be one or several mandatory minimum skill requirements to complete the project. These skills are mandatory requirement for the candidate designers. Therefore, the skill ability and the occupation time should be available for designers before the project manager want to select suitable design project. In here, for the skill, depending on the skills acquisition model of Dreyfus (Dreyfus, 2004), we can identify the skill level as Table 1.

\section{Table 1. Relationship between skill level corresponding rank}

\begin{tabular}{|c|c|c|c|c|c|}
\hline Skill level & Novice & Advanced Beginner & Competent & Proficient & Expert \\
\hline Rank & 0 & 1 & 2 & 3 & 4 \\
\hline
\end{tabular}

The relationship between designer and project can be seen in Figure 3.

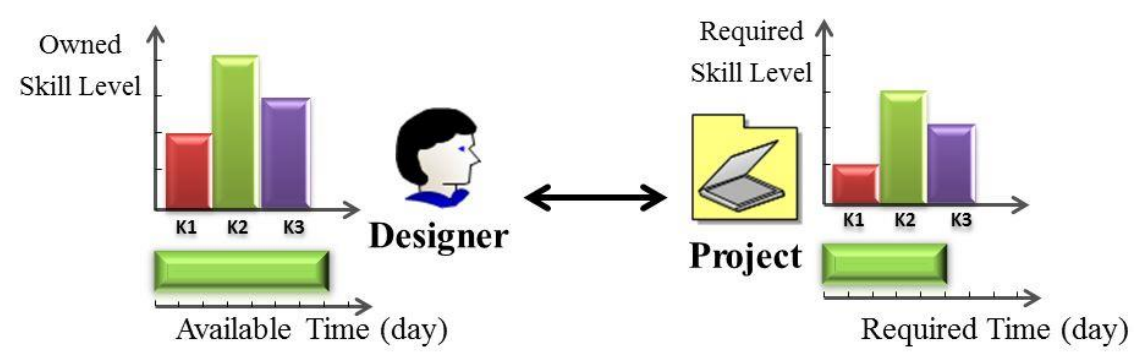

Figure 3. Relationship between designer and project

In the Figure 3, we can find that three skills (K1, K2 and K3) are needed by the project with the different minimum required levels (Advanced Beginner for K1, Proficient for K2 and Competent for K3). Meanwhile, the designer has skill K1, K2 and K3 with the corresponding rank Competent for K1, Expert for K2 and Proficient for K3. Therefore, skill level for the designer is satisfied with project required skill level (the skill K1 $(2>1)$, the skill K2 $(4>3)$ and the skill K3 $(3>2))$. In addition, the available time for the designer also satisfied with the project required time ( 7 days $>5$ days).

\subsection{Calculate the multi-projects expectation level of designer for different combination of projects}

After the first and second step, it is possible for the designers to select the most satisfactory one or several projects for them. We can create the Factors affecting designer expectation like Table 2.

Table 2. Factors and sub-factors affecting designer expectation

\begin{tabular}{|c|c|}
\hline Expectation influence factor $(\mathrm{F})$ & Expectation sub-factor (EF) \\
\hline $\begin{array}{l}\text { Expectation of the personal } \\
\text { responsibility (F1) }\end{array}$ & Task or needed work (EF1) \\
\hline \multirow{4}{*}{$\begin{array}{l}\text { Expectation of the constraints in } \\
\text { design project }(\mathrm{F} 2)\end{array}$} & Project objectives (EF2.1) \\
\hline & Workload (EF2.2) \\
\hline & Project delivery date (EF2.3) \\
\hline & Project requirements (EF2.4) \\
\hline \multirow{3}{*}{$\begin{array}{l}\text { Expectation of work environment } \\
\text { (F3) }\end{array}$} & Design workstyle - teamwork or individualistic (time) (EF3.1) \\
\hline & Design workstyle - virtual or real style (time) (EF3.2) \\
\hline & Workplace environment conditions (EF3.3) \\
\hline $\begin{array}{l}\text { Expectation of salary and welfare } \\
\text { (F4) }\end{array}$ & $\begin{array}{c}\text { Competitive of salary and welfare compare to other similar } \\
\text { organizations (EF4) }\end{array}$ \\
\hline $\begin{array}{l}\text { Expectation personal aspirations } \\
\text { (F5) }\end{array}$ & Career development, ability development (EF5) \\
\hline
\end{tabular}

From the Table 2, we can find that there are 5 main factors (F1, F2, F3, F3, F4 and F5) affect designer expectation, and every main factor has several sub-factors respectively. Depends on the main factors and sub-factors in table 2, we can create the measurement model (Figure 4) to calculate the WTEL (Weight Total Expectation Level) to define the designer's level of expectation with the project. 


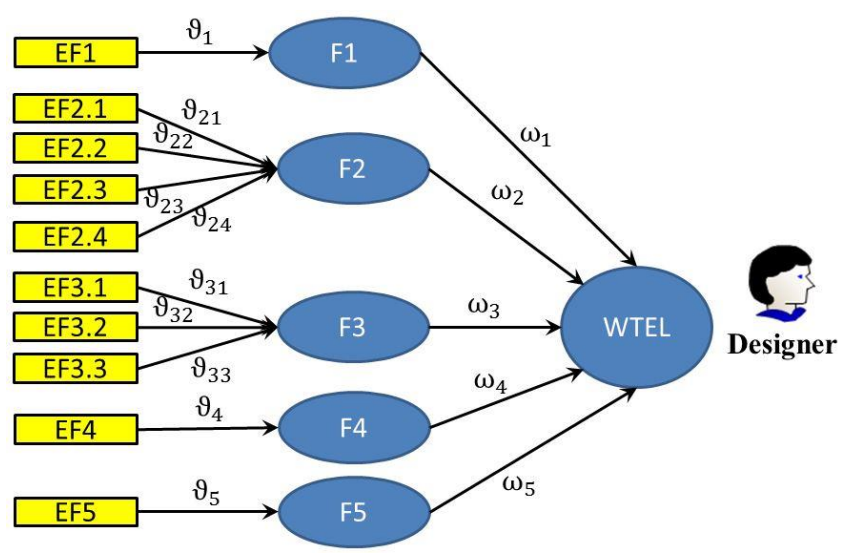

Figure 4. Measurement model of Weighted Total Expectation Level (WTEL) for designer relative to one project

In the measurement model, first of all, we have to let the designer to define the weights of five main factors and all the corresponding sub-factors. The condition of the weights can be seen as the equation (1) through equation (4).

$$
\begin{aligned}
& \sum_{1}^{5} \omega_{i}=1, \\
& \omega_{i} \in[0,1] . \\
& \sum_{j=1}^{N} \vartheta_{i j}=1, \\
& \vartheta_{i j} \in[0,1] .
\end{aligned}
$$

Note. $\omega_{\mathrm{i}}=$ Weight for ith influence factor. $\vartheta_{\mathrm{j}}=$ Weight for jth influence sub-factor. $\mathrm{N}=$ Total number of sub-factors in ith main factor.

Equation (2) means a weight $\omega \in[0,1]$ near 0 represents that the importance of one expectation influence factor is not more important than another expectation influence factor which contains a weight near 1. Meanwhile, the summation of all the values of five (all the expectation influence factors) weights is equal to 1 (equation (1)). Meanwhile, Equation (4) means a weight $\vartheta \in[0,1]$ near 0 represents that the importance of one sub-factor in one expectation influence factor is not more important than another sub-factor which contains a weight near 1. Additionally, the summation of all the values of sub-factors' weight is equal to 1(equation (3)). After that, the designer can evaluate the expectation rank of all the sub-factors. The expectation evaluation criteria for sub-factors are shown as the Table 3.

Table 3. Expectation evaluation criteria for sub-factors

\begin{tabular}{|c|c|}
\hline Expectation & Rank $(\mathrm{Sj})$ \\
\hline Very Dissatisfied & -2 \\
\hline Dissatisfied & -1 \\
\hline Neutral & 0 \\
\hline Satisfied & 1 \\
\hline Very Satisfied & 2 \\
\hline
\end{tabular}

Note. $s_{j}=$ Expectation rank of the $j$ th influence sub-factor.

In the Table 3, the expectation tendency can be divided as 5 ranks from the Very Dissatisfied to the Very Satisfied. The expectation range means the satisfactory level for the designer to the designer expectation influence sub-factors. Through the Table 3 and required project information in Table 2, the designer can define all the ranks for the sub-factors.

Then, we can calculate the WTEL (Weighted Total Expectation Level). The calculation process of the total expectation level for the different expectation influence factors can be seen as the equation (5) through equation (7).

$$
\mathrm{WTEL}=\sum_{1}^{5} \mathrm{~W}_{\mathrm{i}}
$$




$$
\begin{aligned}
& \mathrm{W}_{\mathrm{i}}=\omega_{\mathrm{i}} \cdot \sum_{\mathrm{j}=1}^{\mathrm{N}} \mathrm{V}_{\mathrm{ij}} \\
& \mathrm{V}_{\mathrm{ij}}=\vartheta_{\mathrm{ij}} \cdot \mathrm{s}_{\mathrm{ij}}
\end{aligned}
$$

Note. WTEL $=$ Weighted Total Expectation Level for the designer. $\mathrm{W}_{\mathrm{i}}=$ Weighted expectation of the ith influence factor. $\omega_{\mathrm{i}}=$ Weight for ith influence factor. $V_{j}=$ Weighted expectation of the jth influence subfactor. $\vartheta_{j}=$ Weight for jth influence sub-factor. $s_{j}=$ Expectation of the jth influence sub-factor. $N=$ Total number of sub-factors in ith main factor.

After we calculate to the WTEL, we have to calculate the Average Weighted Total Expectation Level (AWTEL) because of the reason that there will be one or several projects in the multi-project (the different combination of the projects). The calculation process of AWTEL can be seen as equation (8).

$$
A W T E L=\frac{\sum_{m=1}^{M} W T E L_{m}}{M}
$$

Note. AWTEL = Average value of Weighted Total Expectation Level. $\mathrm{M}=$ Number of the projects in the candidate multi-project.

The equation (8) is to calculate the AWTEL of the projects in one candidate multi-project. We can use the AWTEL value to define all the candidate multi-project average weighted expectation levels. After that, we can calculate the sum of AWTEL for all the candidate designers to define the final allocated multi-projects. In here, the higher value of the summation means the all the candidate designers have high expectation with allocated multi-projects.

\subsection{Calculate the collaboration level of designer for different combination of the projects}

The collaboration relationship between two designers can be seen as the Figure 5.

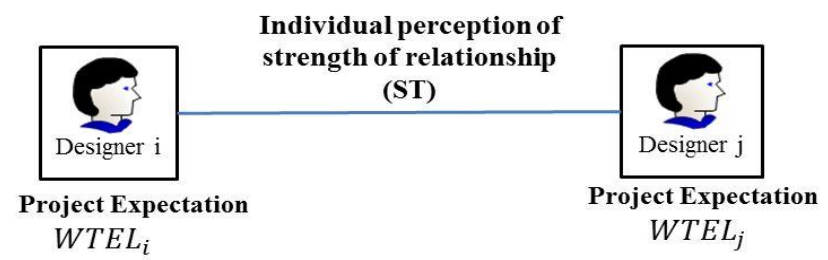

Figure 5. Collaboration relationship between two designers

Through the Figure 5, we can totally understand which kinds of input parameters are needed to calculate collaboration level between to designer. In the Figure 5 we can find that the two designers have their own weighted total expectation level (WTEL) value. Meanwhile, between the two designers, there is individual perception of strength of relationship (ST), which is the social relationship between two designers. The ST will be defined by the two designers. For the criteria to define the ST, we can use Seven Levels of Effectiveness (SLE) (Betz and Pottinga, 2012). Meanwhile, the SLE can help designers to discover how to identify and shift their level of effectiveness with other collaborated designers. Therefore, we can use the SLE to define the criteria of the ST (Table 4).

Table 4. Criteria of individual perception of strength of relationship (ST) from main designer to collaborated designer (Betz and Pottinga, 2012)

\begin{tabular}{|c|c|c|}
\hline SRE & Description & ST values \\
\hline Synchronicity & Focus on creating a positive experience for all & 0.7 \\
\hline Innovation & $\begin{array}{c}\text { Ability to set aside ago perceived restrictions and explore } \\
\text { possibilities from all angles }\end{array}$ & 0.6 \\
\hline Engagement & The desire to bring value, to be a contributor & 0.5 \\
\hline Courage & The willingness to take a stand against previously held negative & 0.4 \\
\hline Frustration & The feeling that the external world must be resisted & 0.3 \\
\hline Fear & Belief that one must protect against almost certain & 0.2 \\
\hline Hopelessness & Fundamental inability to see or work towards a positive future & 0.1 \\
\hline
\end{tabular}

Note. SRE: Strength of relationship effectiveness. 
In Table 4, the strength of relationship can be divided as seven levels, which can just match to the 7 values of ST. In here, the higher value of ST means higher strength of relationship. Meanwhile, if the two collaborated designers don't know the each other, we can select the rank of "Courage" in Table 4 because of the reason that the "Courage" is the median strength. Therefore, depends on the Figure 5 and Table 4, the calculation process of the Total Average Weighted Pair Expectation Gap (TAWPEG) can be seen as equation (9) to equation (11).

$$
\begin{aligned}
& \text { TAWPEG }=\sum_{\mathrm{k}=1}^{\mathrm{J}}\left(A W P E G_{k}\right) \\
& \text { AWPEG }_{k}=\left\{\begin{array}{cr}
\frac{\sum_{i=1}^{M-1} \sum_{j=i+1}^{M}\left(W P S G_{i j}\right)}{\frac{M(M-1)}{2},} & (M>1) \\
0, & (M=0,1)
\end{array}\right. \\
& W P E G_{i j}=\left|W T E L_{i}-W T E L_{j}\right| \frac{S T_{i j}+S T_{j i}}{2}
\end{aligned}
$$

Note. TAWPEG $=$ Total Average Weighted Pair Expectation Gap. $A W P E G_{k}=$ Average Weighted Pair Expectation Gap in kth project. $\mathrm{J}=$ Total number of projects. $\mathrm{M}=$ Total Number of Designers involved in same project. $W S G_{i j}=$ Weighted Expectation Gap between designer $\mathrm{i}$ and designer $\mathrm{j}$. WTEL = Weighted Total Expectation Level. ST $=$ Strength of social relationship between two designers.

Because of the reason that the collaboration relationship (Figure 5) is related to the ST and weighted total expectation level (WTEL), we have to firstly calculate the Weighted Pair Expectation Gap (WPEG $\mathrm{i}_{\mathrm{ij}}$ ) value between two collaborated designers (equation (11)). In here, he reason why we make the subtraction of the WTEL value between two designers is that project expectation gap between two designers will have a direct impact to the collaborative efficiency. The gap is smaller means the collaboration efficiency will be higher. In contrast, the bigger means there are conflicts and disharmony between them, which will reduce collaboration efficiency. Meanwhile, the weight of expectation gap is the average value of ST with each other. After that, we can calculate the Average Weighted Pair Expectation Gap (AWPEG) for all the collaboration pairs in the same project (equation (10)). In the equation (10), we have to calculate sum of the WPSG values for all the collaboration pairs, and then divide this sum by the total number of collaboration pairs $\left(\frac{M(M-1)}{2}\right)$ in the project. In the equation (10), if the $M$ value is equal to 1 , which means only one designer involved in the project, AWPEG value will be 0 because there is no expectation gap between the designer and himself. After that, we can calculate TAWPEG for all the design projects (equation (9)). Then, project manager can use the result of TAWPEG value to define the collaboration ability and assigned final multi-projects to the designers. In here, higher value of TAWPEG means the conflicts between designers are more likely to occur which will cause lower collaboration ability.

\section{ANALYSIS OF AN EXAMPLE}

To analysis the project selection methodology, we will consider about 7 designers (Designer1 to Designer 7) and 10 candidate design projects. The information for the 7 designers and mandatory requirement for the design projects is shows as Figure 6 and Table 5

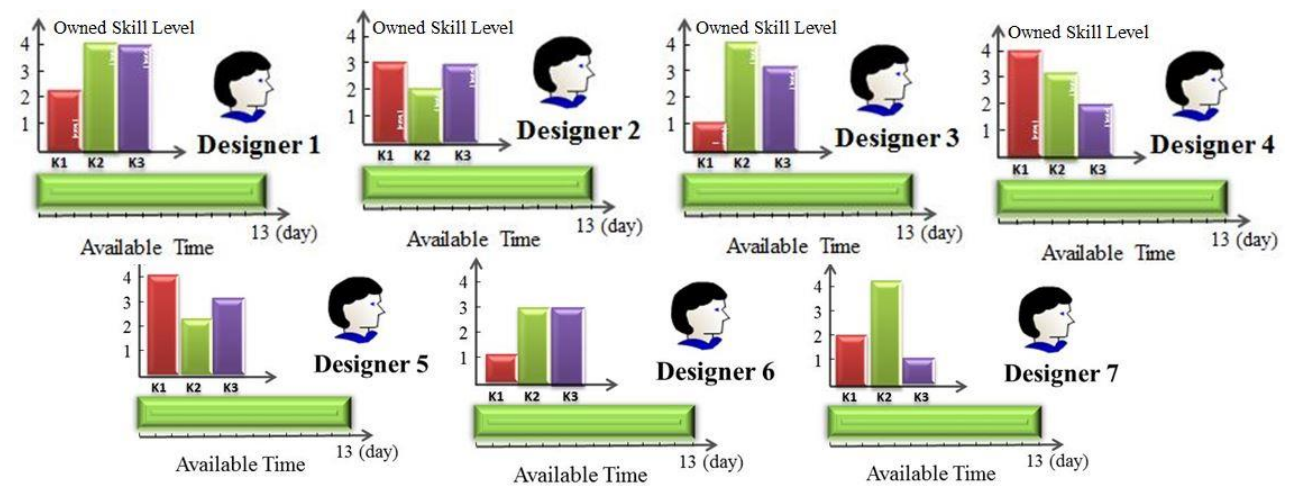

Figure 6. Owned skill level and available time for designer 
Table 5. Mandatory skill requirements and required time for the candidate design projects

\begin{tabular}{|c|c|c|c|c|c|}
\hline Project & K1 & K2 & K3 & RT & NRD \\
\hline Project1 & 3 & 2 & 2 & 2 & 4 \\
\hline Project2 & 1 & 3 & 3 & 2 & 2 \\
\hline Project3 & 4 & 2 & 4 & 2 & 1 \\
\hline Project4 & 1 & 2 & 4 & 6 & 2 \\
\hline Project5 & 0 & 3 & 2 & 3 & 1 \\
\hline Project6 & 1 & 3 & 3 & 1 & 1 \\
\hline Project7 & 2 & 4 & 4 & 7 & 4 \\
\hline Project8 & 2 & 2 & 1 & 3 & 1 \\
\hline Project9 & 3 & 2 & 4 & 1 & 2 \\
\hline Project10 & 2 & 3 & 4 & 7 & 3 \\
\hline
\end{tabular}

Note. $\mathrm{K} 1=$ Skill $1 . \mathrm{K} 2=$ Skill $2 . \mathrm{K} 3=$ Skill 3. $\mathrm{RT}=$ Required Time for the project. NRD $=$ Number of Required Designers

Through the Figure 6 and Table 5, we can find that the Project3, Project4, Project7, Project9 and Project10 can be directly filtered because all the required skill levels or the required time for these projects are larger than owned skill levels for the 7 designers. After that, there will be different combination of the projects for every designer which can let 7 designers meet the available time and project required designers. After the filtering, 42 multi-project combination types will be selected.

After that, we can analyse the designers' expectation level. The designers can define the weight and rank for every expectation factors in Table 2. In here, because this is from the perspective of the designer's own interests, the evaluation result of the designer will directly lead to its own work comfort, so the quality of input information will be guaranteed by the designer himself. Then, we can use equation (1) through equation (8) to calculate the AWTEL value. The example of evaluation of expectation factors (Project 2) and the result value of AWTEL for all the multi-projects for the Designer1 is shown as Table 6 and Table 7.

Table 6. Evaluation result of the expectation factors in Project 2 for designer1

\begin{tabular}{|c|c|c|c|c|}
\hline SIF & $\omega_{i}$ & Expectation sub-factor (EF) & $\vartheta_{i j}$ & Rank \\
\hline F1 & 0.1 & Generate clear ideas, concepts and designs for creative assets (EF1) & 1 & 2 \\
\hline \multirow{4}{*}{$\mathrm{F} 2$} & \multirow{4}{*}{0.3} & Delivering an industry-leading offering (EF2.1) & 0.2 & -1 \\
\hline & & 3 types of weblogs software, 2 types of desktop software(EF2.2) & 0.1 & -2 \\
\hline & & October 2, 2018(EF2.3) & 0.3 & 1 \\
\hline & & User can see public blog posts, comment on public blog posts(EF2.4) & 0.4 & 1 \\
\hline \multirow{3}{*}{ F3 } & \multirow{3}{*}{0.2} & Work with all team members all time (100\% time)(EF3.1) & 0.2 & -1 \\
\hline & & $30 \%$ time with virtual work and $70 \%$ time with real work (EF3.2) & 0.4 & 2 \\
\hline & & $\begin{array}{l}\text { Adjustable chairs, task lights, sit-to-stand desks and keyboard trays } \\
\text { so designers can adjust their workspaces to meet their needs (EF3.3) }\end{array}$ & 0.4 & 0 \\
\hline F4 & 0.2 & $\begin{array}{c}400 € \text { of salary, the health insurance, a generous } 401 \mathrm{~K} \text {, the } \\
\text { opportunity for a bonus and more (EF4) }\end{array}$ & 1 & 1 \\
\hline F5 & 0.2 & Knowledge and experience in weblogs software development (EF5) & 1 & 1 \\
\hline
\end{tabular}

Note. SIF $=$ Expectation Influence Factor. F1 = Expectation of the personal responsibility. F2 = Expectation of the constraints in design project. F3 = Expectation of work environment. F4 = Expectation of salary and welfare. F5 = Expectation personal aspirations.

Depends on the Table 6, and equation (5) through equation (7), The Weighted Total Expectation Level (WTEL) for project 2 is $0.81(1 \times 2 \times 0.1+(0.2 \times(-1)+0.1 \times(-2)+0.3 \times 1+0.4 \times 1) \times 0.3+(0.2 \times(-1)+$ $0.4 \times 2+0.4 \times 0) \times 0.2+1 \times 1 \times 0.2+1 \times 1 \times 0.2)$. After that, we can calculate the sum of AWTEL values for all the 42 multi-project combination types. The 8 highest sum of AWTEL value is shown as Table 7 . 
Table 7. 8 highest sum of AWTEL value for all the 42 multi-project combination types

\begin{tabular}{|c|c|c|c|c|c|c|c|c|}
\hline \multirow{2}{*}{ Type } & \multicolumn{7}{|c|}{ Multi-project combination types: } & Sum of \\
\cline { 2 - 8 } & Designer1 & Designer2 & Designer3 & Designer4 & Designer5 & Designer6 & Designer7 & AWTEL \\
\hline T1 & P2 & P1, P8 & P2, P5 & P1 & P1 & P1, P5, P6 & P8 & 3.9 \\
\hline T2 & P2 & P1, P8 & P2 & P1 & P1 & P1, P5, P6 & P8 & 3.9 \\
\hline T3 & P2 & P1, P8 & P2, P5 & P1 & P1 & P1, P6 & P8 & 3.9 \\
\hline T4 & P2 & P1, P8 & P2, P5, P6 & P1 & P1 & P1, P5 & P8 & 3.9 \\
\hline T5 & P2 & P1 & P2, P5 & P1 & P1 & P1, P5, P6 & P8 & 3.9 \\
\hline T6 & P2 & P1, P8 & P2, P5, P6 & P1 & P1 & P1, P5, P6 & P8 & 3.9 \\
\hline T7 & P2 & P1, P8 & P2, P6 & P1 & P1 & P1, P5 & P8 & 3.9 \\
\hline T8 & P2 & P1 & P2 & P1 & P1 & P1, P5, P6 & P8 & 3.8 \\
\hline
\end{tabular}

Note. $\mathrm{P}=$ Project

From the Table 7, we can find that the 7 multi-project combination types (T1, T2, T3, T4, T5, T6 and T7) have the same highest sum value of AWTEL (3.9). Therefore, we have to identify these 7 types through analysing the collaboration ability. To calculate the TAWPEG value, we have to understand the ST between every two collaborated designers. The ST among the 7 designers is shown as Figure 7.

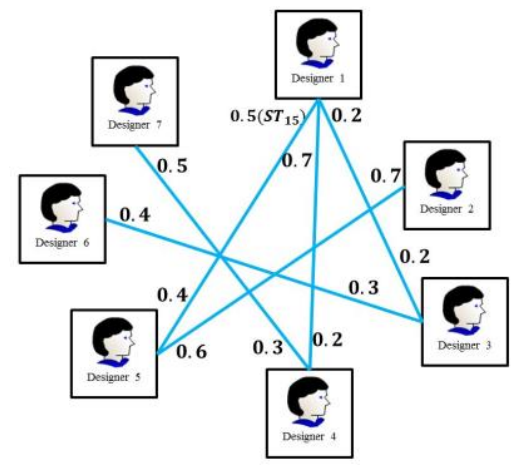

Figure 7. Individual perception of strength of relationship (ST) among 7 designers

In the Figure 7, there are 6 pairs of designer know each other (blue line), and they can define the different ST value with each other. Even though, other pairs they do not know each other, we can set the we can set the rank of "Courage" (ST value 0.4$)$ in Table 4. Therefore, there will be totally $21\left(\frac{7 \times(7-1)}{2}\right)$ pairs of social relationship with the different ST values with each other. Therefore, through the result of Table 7, Figure 10, and equation (10) to equation (11), we can calculate the AWPEG value for Project1 in Type1 (T1) multi-project combination (Table7). The result of AWPEG value for project1 is 0.061

$$
\left(\frac{|0.58-0.45| \times \frac{0.4+0.4}{2}+|0.58-0.65| \times \frac{0.6+0.7}{2}+|0.58-0.72| \times \frac{0.4+0.4}{2}+|0.45-0.65| \times \frac{0.4+0.4}{2}+|0.65-0.72| \times \frac{0.4+0.4}{2}}{\frac{4(3-1)}{2}}\right) .
$$

Meanwhile, we can use the same way to calculate AWPEG value for other projects in the Type1. After that, according to equation (9) to release TAWPEG value for all the 7 same highest sum of AWTEL value of multi-project combinations (T1, T2, T3, T4, T5, T6 and T7 in Table 7)(Table 8).

Table 8. TAWPEG values for 7 same highest sum of AWTEL value of multi-project combinations in Table 8

\begin{tabular}{|c|c|}
\hline Type & TAWPEG \\
\hline T1 & 0.100 \\
\hline T2 & 0.106 \\
\hline T3 & 0.106 \\
\hline T4 & 0.130 \\
\hline T5 & 0.094 \\
\hline T6 & 0.165 \\
\hline T7 & 0.106 \\
\hline
\end{tabular}

Note. $\mathrm{TAWPEG}=$ Total Average Weighted Pair Expectation Gap. 
In the Table 8 we can find that even though the sum of AWTEL values are the same among 7 types in Table7, the TAWPEG values are different. Meanwhile, the T5 multi-project combination (project2 for designer1, project1 for designer2, project2 and project5 for designer3, project1 for designer4, project1 for designer5, project1, project5 and project6 for designer6, and project8 for designer7) get the smallest value of TAWPEG. Therefore, the project manager should position multi-project to the designer depends on the T5.

\section{DISCUSSION AND CONCLUSION}

This article proposes a design project selection methodology with the consideration of expectation of designer to the design projects and collaboration ability of designer. For the expectation of designer to the design projects, we have consider about five main factors (Expectation of the personal responsibility, Expectation of the constraints in design project, Expectation of work environment, Expectation of salary and welfare, and Expectation of personal aspirations), which consist of different sub-factors respectively, that influence the designer. Then, through the result of Average Weighted Total Expectation Level (AWTEL) in Table 7, project manager can find the most satisfactory combination (highest value of AWTEL) of design projects for designers. In here, the higher value of AWTEL means the better of the expectation of designer to the multi-project. After that, if the AWTEL values are the same among different combination projects, we can analysis collaboration ability of designer in the different combination projects to identify them. For the factors of collaboration ability between two designers, we mainly consider the factors of individual perception of strength of relationship (ST) and project expectation gap between two designers in same involved project. Then, through the result of Total Average Weighted Pair Expectation Gap (TAWPEG) value in Table 8, project manager can find and select smallest value of the multi-project combination. In here, the smaller value of TAWPEG means the better of the collaboration in the positioned multi-project. Therefore, through this methodology, project manager can select most expectative and collaborative multi-projects to the designers.

\section{REFERENCES}

Babu, A. J. G. and Suresh, N. (1996), "Project management with time, cost, and quality considerations." European Journal of Operational Research, Vol. 88 No. 2, 320-327.

Betz A. and Pottinga U. (2012), The seven levels of personal, group and organizational effectiveness. BEabove Leadership. http://www.beaboveleadership.com/

Engwall, M. and Jerbrant, A. (2003), “The resource allocation syndrome: the prime challenge of multi-project management?” Int. J. Proj. Manag. Vol. 21 No. 6, 403-409. http://dx.doi.org/10.1016/s02637863(02)00113-8.

Girard, P. and Robin, V. (2006), "Analysis of collaboration for project design management." Computers in industry, Vol. 57 No. 8, 817-826.

Gubbi, J., Buyya, R., Marusic, S. and Palaniswami, M., (2013), "Internet of Things (IoT): A vision, architectural elements, and future directions." Future generation computer systems, Vol. 29 No. 7, 1645-1660.

Kaiser, M. G., El Arbi, F. and Ahlemann, F. (2015), "Successful project portfolio management beyond project selection techniques: Understanding the role of structural alignment." International Journal of Project Management, Vol. 33 No. 1, 126-139.

Karageorgos, A., Rapti, E. and Gerogiannis, V. C. (2015), "Resource Allocation in Software Projects using a Bio-inspired Model." Journal of Software, 19-20.

Lee, J., Bagheri, B. and Kao, H. A. (2015), “A cyber-physical systems architecture for industry 4.0-based manufacturing systems." Manufacturing Letters, Vol. 3, 18-23.

Loredo, E. O. and Picos, C. (2014), The Influence of the Human Resource Allocation Process on Employee Satisfaction Level (Doctoral dissertation, Master Thesis, Umea School of Business and Economics, Umea, SE).

Maslow, A. H. (1943), “A theory of human motivation.” Psychological review, Vol. 50 No. 4, 370.

McLeod, S. (2007), "Maslow's hierarchy of needs.” Simply Psychology, Vol. 1.

Men, L. R. (2014), "Strategic internal communication: Transformational leadership, communication channels, and employee satisfaction." Management Communication Quarterly, Vol. 28 No. 2, 264-284.

Stringer, L. (2013), Workplace strategies that enhance human performance, health and wellness.

Tavana, M., Abtahi, A. R. and Khalili-Damghani, K. (2014), "A new multi-objective multi-mode model for solving preemptive time-cost-quality trade-off project scheduling problems." Expert Systems with Applications, Vol. 41 No. 4, 1830-1846. 